\title{
Imaginário coletivo: estudos do sensível na teoria do jornalismo'
}

\begin{abstract}
RESUMO
Estudar o imaginário na imprensa supõe, de antemão, questionar os fundamentos que vêm sustentando uma Teoria do Jornalismo bastante difundida no ensino e pesquisa desta área no país - os da objetividade, imparcialidade, clareza e exatidão. Inserida na camisa-de-força da realidade factual e comprovável empiricamente, esta teoria ignora ou recusa as manifestações sensíveis e emocionais, simbólicas e míticas do mundo imaginário, percebidas aquém e além do que nos mostram os recursos do racionalismo e que estão presentes rotineiramente nas temáticas diversas da cobertura jornalística. A questão exige discutir o conceito de imaginário na relação entre sensibilidade e razão, fazendo a opção por uma teoria mais aberta e ampla para investigar o fenômeno jornalístico, o que requer não somente um gesto mais acolhedor quanto à relevância do cotidiano e do senso comum nas teorias jornalísticas, mas uma atitude epistemológico-metodológica mais compreensiva do que explicativa.
\end{abstract}

\section{PALAVRAS-CHAVE}

Jornalismo

Imaginário

Epistemologia

\section{ABSTRACT}

The study of imaginary in press pressuposes, beforehand, a questioning of the basic principles that have come to steer a theory of journalism very much at hand in teaching and in journalistic reaserch in the country. Relying on notions of objectivity, impartiality, clarity and exactitude and forced into the straightjacket of factual and empirically confirmed reality, such theory ignores or refuses to take into consideration emotional and subjective, symbolic and mytical manifestations that are part of imaginary, perceived as beyond and below what rational resources can entail us and routinely present in many press coverage themes. Such questioning demands an investigation of the concept of imaginary and the relationship between reason and sensibility, turning it into an open ended and wider theory to investigate journalistic phenomena, this deserves not only a more welcoming act to the role of common sense and of day to day knowledge in journalistic theories but also demands a more understanding than explicative methodological-epistemological attitude.

\section{KEYWORDS}

Journalism

Imaginary

Epistemology

\section{Gislene Silva}

Professora do Programa de Pós-Graduação em Jornalismo da UFSC/SC/BR.

gislenedasilva@gmail.com 
Para pensar a Teoria do Jornalismo pela via das potencialidades dos estudos do imaginário como recurso teórico e metodológico parto de três pressupostos. Primeiramente, o de que estudar o imaginário na imprensa supõe, de antemão, questionar os fundamentos que vêm sustentando uma Teoria do Jornalismo bastante difundida no ensino e pesquisa desta área no país - os da objetividade, imparcialidade, clareza e exatidão. Inserida na camisa-de-força da realidade factual e comprovável empiricamente, esta teoria ignora ou recusa as manifestações sensíveis e emocionais, simbólicas e míticas do mundo imaginário, percebidas aquém e além do que nos mostram os recursos do racionalismo e que estão presentes rotineiramente nas temáticas diversas da cobertura jornalística.

Como diz Michel Maffesoli, em referência específica a expressões do onírico, "a publicidade, os vídeos-clipes, a produção cinematográfica, as diversões de toda ordem, a multiplicidade de festas estão aí para prová-lo" (Maffesoli, 1998, p. 156). Eu incluo aí o jornalismo, tomando-o sempre como um dos fenômenos da mídia, sendo parte, portanto, dos interesses, cuidados e críticas do pensamento teórico do campo da Comunicação. Maffesoli, ao investir no sentimento coletivo e suas consequências, tanto sociais quanto políticas, tanto para melhor ou para pior, defende uma razão sensível que integre a sensibilidade no ato do conhecimento. Tratando dos afetos e das vibrações comuns, ele explicita:

Não há domínio que esteja indene da ambiência afetual do momento. A política, evidentemente, que se tornou um vasto espetáculo de variedades que funcionam mais sobre a emoção e a sedução do que sobre a conviç̧ão ideológica; mas, igualmente, o trabalho, onde a energia libidinal exerce um papel importante; e não esquecendo todas as efervescências musicais e esportivas que são tudo menos racionais. Tudo isso mostra que existe uma dialética entre o conhecimento e a experiência dos sentidos (Maffesoli, 1998, p. 192).

Teria relevância, então, reconhecer para conhecer a presença de imaginários no jornalismo e, como seu duplo, a inserção de instâncias sensíveis na teoria do jornalismo, dura e fria.

Depois, pressuponho que, ao tratar de imagens arquetípicas, metáforas de base, grandes imagens, imagens-matrizes, a imagem possa ser compreendida como manifestação sensível do abstrato ou do invisível - algo próximo de imagem literária, afetada pela psique, pelo consciente e inconsciente, pelos devaneios e sonhos, e não apenas como imagem pictórica, acoplada a suportes iconográficos. Tal como sugere Sodré, levo em consideração a imagem subjetiva ou interna, sendo que imagem faz referência não apenas ao sentido da visão, mas também a qualquer modalidade sensorial. "Embora diferindo essencialmente da sensação, a imagem subjetiva a esta se assemelha em alguns aspectos, como o das mesmas reações diante de um objeto ou do prolongamento imagético da sensação. Assim, as imagens internas podem ser visuais, auditivas, gustativas, olfativas e táteis" (Sodré, 2006, p. 81).

Semelhante ideia encontra-se na perspectiva de Maffesoli: “Não é a imagem que produz o imaginário, mas o contrário. A existência de um imaginário determina a existência de um conjunto de imagens. A imagem não é o suporte, mas o resultado" (Maffesoli, 2008, p. 76). Temos ainda, pela observação básica de Juremir Machado da Silva (2006, p. 9), que o imaginário deve sempre ser entendido como algo mais amplo que um conjunto de imagens. O imaginário não seria um mero álbum de fotografias mentais nem um museu da memória individual ou social. Tampouco se restringiria ao exercício artístico da imaginação sobre o mundo. "O imaginário é uma rede etérea e movediça de valores e sensações partilhadas concreta ou virtualmente".

Como terceiro pressuposto, retorno ao entendimento de que os sentimentos excedem a esfera do individual e do privado e se estendem para os domínios sociais e de que a memória e as produções simbólica, imaginativa, mítica e imaginária têm caráter também social, coletivo. Portanto, na relação entre imaginário e jornalismo interessa o aspecto coletivo, a manifestação social do imaginário, uma vez que o fenômeno da comunicação noticiosa é de natureza igualmente social e coletiva. O imaginário circularia através da história, das culturas e dos grupos sociais, como um fenômeno coletivo, social e histórico (Legros et al., 2005 , p. 10). Ele resultaria de um trajeto antropológico (Durand, 1997) - sobre o qual voltarei a falar mais adiante.

$\mathrm{Na}$ prática do jornalismo, há exemplos de experiências da subjetividade que orientam a apuração e redação de notícias e reportagens. Há igualmente o reconhecimento e conhecimento reflexivo a este respeito, como uma guinada subjetiva (Serelle, 2009), uma narrativa jornalística para 
além dos faits-divers (Albuquerque, 2000), uma ficcionalidade do relato jornalístico (Vogel, 2005) ou um falar não mais para as massas, mas falar com o outro (Resende, 2010), e muitos outros estudos. No campo da Comunicação, poderíamos dizer que há atualmente inquietações teóricas voltadas para o subjetivo, e não apenas no que tange às interações comunicativas no nível interpessoal, mas no que importa ao processo comunicacional mediado, à mídia. Ou, se preferirmos a síntese, no que diz respeito à condição midiática, ao todo bios midiático (Sodré, 2006). Muniz Sodré propõe uma teoria compreensiva da comunicação que possa observar as estratégias sensíveis na relação mídia e política e que seja "capaz de trazer mais luz ou hipóteses mais fecundas sobre as transformações das identidades pessoais e coletivas, as modulações da política e as ambivalências do pluralismo cultural no âmbito da globalização contemporânea" (Sodré, 2006, p. 70).

Tratar-se-ia de investigar uma dimensão primordial, que tem mais a ver com o sensível do que com a medida racional, que reconhece a potência emancipatória contida no sensível e no afetivo, para além dos cânones limitativos da razão instrumental (Sodré, 2006, p. 13). Também para Martín-Barbero a presença dessas dimensões afetivas que os meios de comunicação potencializam não despolitiza a ação. "Se trata de la reintrodución, en el ámbito de la racionalidad formal, de las mediaciones de la sensibilidad que el racionalismo del "contrato social" creyó poder (hegelianamente) superar" (Martín-Barbero, 2008).

É por tais dimensões sensíveis ou afetivas que passam os estudos do imaginário. Mas o imaginário tem muitas vezes sido tomado conceitualmente como muito próximo dos conceitos de representação social, imagem mental, ideologia, crença, atividade simbólica, cultura e imaginação. Cada um desses termos, no entanto, tem complexas matrizes teóricas e disciplinares (ver Legros; Silva, J.M.; Susca; Maffesoli, 2008). Para pensar o fenômeno do jornalismo como expressão do imaginário coletivo, interessa aqui tomar o imaginário pela conceituação de Gilbert Durand, cujo lastro, por sua vez, vem pela linha teórica por onde passaram Simmel, Jung, Eliade e Bachelard.

Tais autores - e outros como Morin, Mafessoli e Juremir Machado da Silva, e mesmo Castoriadis - elaboram um olhar mais positivo sobre o imaginário, quando este costuma ser visto quase sempre como oposição ao real, ou seja, como fal- sidade, fuga, ilusão, não-real. É que a boa vontade para com a vida imaginária nos dias de hoje ainda se dá num ambiente ora de discreta desconfiança ora de hostilidade contra os estudos do imaginário. Geralmente enclausurada nos desvios e mistérios da psique, limitada ao universo das culturas arcaicas, recolhida ao mundo das artes, só muito lentamente a problemática do imaginário vem ganhando visibilidade nas ciências sociais.

Durand chega a constatar, em muitas disciplinas do saber, a formação de uma "ciência do imaginário", que vem desmistificando as proibições e os exílios impostos à imagem pela civilização que criou essas mesmas disciplinas (Durand, 1998, p. 71 e 77). Em seu livro As estruturas antropológicas do imaginário, de 1960, depois de criticar vários teóricos e recensear inúmeras posturas conceituais, Durand conclui que todos eles, incluindo Bergson, Sartre, Barthes e a própria psicanálise freudiana e a etnologia estruturalista, apesar de contribuírem para o resgate do mundo das imagens, minimizaram a imaginação e deixaram evaporar a eficácia do imaginário.

Na sociedade contemporânea, em que a vida cotidiana, mais do que em outros tempos, é mediada pela imagem, principalmente pelas imagens da mídia, Durand diz, ao estudar o paradoxo do imaginário no Ocidente (Durand, 1998, p. 9-34), que, por um lado, a nossa civilização propiciou ao mundo as técnicas de reprodução da comunicação de imagens, sempre em constante desenvolvimento, mas, por outro, junto à filosofia fundamental, demonstrou uma desconfiança iconoclasta endêmica. No entanto, Durand acredita que todo o esforço do Ocidente em conferir um imperialismo ideológico à ciência, como única dona de uma verdade iconoclasta e fundamento supremo dos valores, foi "um trabalho em vão, pois as imagens, expulsas pela porta da frente, reentravam pela janela para atacar os conceitos científicos mais modernos como as ondas, os corpúsculos, as catástrofes" (Durand, 1998, p. 68).

Com atenção na entrada do imaginário como objeto de conhecimento no pensamento social, temos que, apesar do modo lento, as ciências humanas e sociais passaram a se interessar pelo estudo do imaginário há mais tempo do que as ciências da comunicação. No livro Sociologia do imaginário, os pesquisadores franceses Legros, Monneyron, Renard e Tacussel rastreiam o imaginário entre os fundadores da sociologia (passando por Marx e Engels, Tocqueville, Le Bom, Tar- 
de, Preto, Durkheim, Weber e Simmel), apontam os fundadores de uma sociologia do imaginário (lembrando, entre tantos, de Mannheim, Mauss, Bataille, Benjamin, Sansot, Callois), até chegar aos pesquisadores contemporâneos (Halbwachs, Durand, Bachelard, Barthes, Castoriadis, Morin, Baudrillard, Maffesoli).

Já na introdução, os autores avisam que sociologia do imaginário não é um campo definido por um objeto e sim um ponto de vista sobre o social: ela se interessa pela dimensão imaginária de todas as atividades humanas, pela dimensão mítica da existência social. O mesmo quero dizer sobre o estudo de imaginários na mídia noticiosa. Ou seja, também interessa à Teoria do Jornalismo o enraizamento arquetipal, o homo imaginans e não somente o homo rationalis.

As palpitações, criaturas e as recriações do imaginário coletivo são, portanto, testemunhos vivos - intangíveis, mas estruturantes, presentes em nossa vida onírico-emocional mesmo antes que a elaboração racional - de modalidades através das quais se vai transformando a experiência vivida, o modo de habitar o mundo. [...] devemos nos deter seriamente sobre cada faceta, detalhe, máscara propostos e projetados pelo imaginário coletivo, olhar por trás deles, escondidos dentro dos abalos e custódias, na hilaridade mais boba ou na agressividade mais rude que possuem, qualquer coisa que na realidade os transcende no momento mesmo em que se lhes dá a vida. A sociologia do imaginário tem, portanto, a possibilidade de sugerir qual potência-tendência social alinha no coração da sociedade espetacular (Susca, 2007, p. 79-80).

Para observar e descrever fragmentos desses testemunhos de imaginários na imprensa, faz-se necessária a retomada de algumas definições do que seria, então, o imaginário coletivo. Parte dos estudos do imaginário dedica-se a observar a relação das imagens com a vida cotidiana (outras atuam nos estudos da ficção, em especial na literatura e cinema, e nas visões de mundo da política, religião, ciência).

"O imaginário não é uma forma social escondida, secreta, inconsciente que vive sob as fibras do tecido social. Ele não é o reflexo, o espelho deformado, o mundo revirado ou a sombra da realidade, uma sociedade subterrânea que cruzará profundamente os esgotos da vida cotidiana, mas ele estrutura, no fundo, o entendimento humano." (Legros et al., 2007, p. 111). Com foco no cotidiano, e citando Tacussel, os autores argumentam que o imaginário sublinha como a experiência vivida, o labirinto das relações afetivas e o movimento tumultuoso das paixões "se concretizam em um cenário coletivo, simultaneamente banal e trágico, no qual a mitologia (os heróis, os mártires, as vitimas sacrificiais, os ídolos do esporte ou da canção, os faits divers extraordinários ou as superstições domésticas) habita as formas sociais" (Legros et al., 2007, p. 100).

Na avaliação de Legros (2007) e demais autores do livro, Maffesoli se impôs como o principal teórico da sociologia do imaginário, ao sugerir que essa "matéria subterrânea das coisas" assegura a coerência secreta do natural e do cultural, do espaço social e do sentimento estético - eu diria que essa matéria nem tão subterrânea e esse caráter nem tão secreto podem ser desvendados, ou melhor, explicitados pelo exercício da pesquisa.

Em Maffesoli, o imaginário - que para ele é coletivo na maior parte do tempo - se constitui pela ideia de fazer parte de algo, de partilhar uma filosofia de vida, uma linguagem, uma atmosfera, uma ideia de mundo, uma visão das coisas, na encruzilhada do racional e do não-racional. Muito de seu entendimento a respeito do que é o imaginário está claramente resumido em uma entrevista que o pesquisador deu a uma revista acadêmica brasileira (Maffesoli, 1998).

Entre muitas considerações, Maffesoli vê o imaginário como (a) uma força social de ordem espiritual, uma construção mental, que se mantém ambígua, perceptível, mas não quantificável, (b) um estado de espírito de um grupo, de um país, de um Estado-nação, de uma comunidade; (c) como promotor de vínculo, cimento social; (d) como detentor de um elemento racional (assim como a ideologia), mas de também outros parâmetros como o onírico, o lúdico, fantasia, o imaginativo, o afetivo, o não-racional, os sonhos; (e) o imaginário não seria de direita nem de esquerda, pois estaria aquém ou além desta perspectiva moderna; (f) o imaginário atravessaria todos os domínios da vida e concilia o que aparentemente é inconciliável, por isso mesmo os campos mais racionais, como as esferas política, ideológica e econômica, seriam recortados pelo imaginário, que tudo contamina.

Além de coletivo, o imaginário transitaria entre passado e futuro. Nos termos de Juremir Machado da Silva, ele seria reservatório e mo- 
tor. Como reservatório, o imaginário agregaria imagens, sentimentos, lembranças, experiências, visões do real, leituras de vida e, através de um mecanismo individual/grupal, sedimentaria um modo de ver, de ser, de agir, de sentir e de estar no mundo. Como motor, elemento propulsor, o imaginário retorna ao real, seria um sonho que realiza a realidade, funcionando como catalisador, estimulador e estruturador das práticas. Assim, afirma o autor, todo indivíduo submete-se a um imaginário preexistente e todo sujeito é um inseminador de imaginários (Silva, J. M., 2006, p. 09-12).

Nesta questão específica do imaginário estar olhando tanto para trás como para frente, Patai argumenta que o importante não é considerar a sobrevivência do passado no presente, mas o exame das forças e processos mitopoéticos vivos que atuam em nossa cultura, como resultado de um real dinamismo psicossocial que opera na psique do homem moderno em grau tão intenso quanto aquele em que operou em gerações do passado remoto. Portanto, além de considerar o residual, inclusive em forma de memória, é necessário tomar essas imagens primordiais como "depósitos das experiências constantemente repetidas da humanidade" cuja direção é voltada para orientar o futuro (Patai, p. 29).

Todas essas reflexões sobre o que é o imaginário são tributárias de Gilbert Durand, que propõe uma teoria geral do imaginário ou uma antropologia do imaginário. Interessa-nos, no pensamento de Durand, mais do que seu levantamento crítico e suas estruturas para apreender o imaginário, a vitalidade por ele atribuída ao recurso antropológico, que nos permite avançar no entendimento do imaginário como um fenômeno concomitantemente individual e social, mítico e histórico.

Ao longo de suas obras, Durand elabora alguns conceitos de imaginário: conjunto de imagens e relações de imagens que constitui o capital pensado do homo sapiens; faculdade da simbolização de onde todos os medos, todas as esperanças e seus frutos culturais jorram continuamente desde os cerca de um milhão e meio de anos que o homo erectus ficou de pé na face da Terra. Como bom discípulo de Bachelard, defende uma lógica não linear, constelacional, em que a única coisa normativa é o universo das grandes reuniões plurais de imagens em constelações, enxames, poemas ou mitos. Chega a falar em alógica, a outra lógica que rege o imaginário em suas manifestações mais típicas: o sonho, o onírico, o mito, o rito, a narrativa da imaginação - e, por que não acrescentarmos, parte da literatura, da ficção cinematográfica (como faz Morin), da própria mídia e mesmo do jornalismo.

Uma ideia condensa, de certa maneira, o pensamento de Durand: a de trajeto antropológico, que ele define como "incessante troca que existe ao nível do imaginário entre as pulsões subjetivas e assimiladoras e as intimações objetivas que emanam do meio cósmico e social" (Durand, 1997, p. 41)2. Este trajeto tem duas mãos, partindo tanto do cultural como do psicológico, uma vez que o essencial da representação e do símbolo está contido entre esses dois marcos reversíveis. Em outras palavras, "o trajeto antropológico representa a afirmação na qual o símbolo deve participar de forma indissolúvel para emergir numa espécie de vaivém contínuo nas raízes inatas da representação do sapiens e, na outra ponta, nas várias interpelações do meio cósmico e social" (Durand, 1998, p. 90).

Em outros termos, o trajeto antropológico seria o movimento em que os símbolos, transitando entre motivações subjetivas e objetivas, ganham sentido; ou seja, as imagens se formam pela interação da subjetividade com o meio material e social, o imaginário se dá na confluência do subjetivo e do objetivo, do mundo pessoal e do meio cósmico ambiente. O imaginário, longe de aparecer como um momento ultrapassado na evolução da espécie, manifesta-se como elemento constitutivo e instaurativo do comportamento específico do Homo sapiens (Durand, 1997, p. 429).

As visões que costumamos ter do Homo sapiens privilegiam o Homo sapiens-faber, o ser racional e produtor de ferramentas, e com isso afastamos tudo o que diz respeito à fantasia, ao sonho, ao imaginário. Aqui a validade da abordagem de Morin, quando discute a reintrodução do imaginário e do mitológico na definição fundamental do homem. "Por isso, é preciso falar do Homo sapiens-demens. Cada um dos termos reconduz ao outro sem que se saiba jamais muito bem qual é o momento em que se é sapiens ou demens" (Morin, 2000, p. 190). Ao refletir sobre o homem imaginário, também Morin aponta a complementaridade entre extrospecção sociológica e introspecção psicológica, espaço onde estariam escondidas as mensagens secretas, a mais profunda intimidade da alma e as carências universais e as do século presente (Morin, 1997, p. 245). 
Na proposta particularíssima de Durand, ele parte da hipótese de que existe uma estreita concomitância entre os gestos do corpo, os centros nervosos e as representações simbólicas, e elege três gestos dominantes do imaginário: o postural (verticalidade), digestivo (descida) e o copulativo (ritmo). Na base da organização das imagens, o autor percebe duas fundamentações, ou dois regimes: o diurno (da posição, das armas, do masculino, da elevação e purificação) e o noturno (da nutrição, do feminino, do ciclo). O regime diurno seria o das oposições, das separações, divisões, lutas, e o noturno seria o das conciliações, unificações, complementações.

Nessas convergências e cruzamentos, Durand postula certos protocolos normativos das representações imaginárias, agrupados em estruturas - estruturas implicadas em dinamismo transformador. Na opinião de Durand, é Bachelard quem enxerga a plenitude das imagens e o dinamismo criador do imaginário. Inspirado em seu pensamento, Durand quer insistir na diferença entre imagem e palavra, entre signo e símbolo e afirmar que o símbolo não é do domínio da semiologia, mas de uma semântica especial, menos arbitrária.

\section{Na minha hipótese, o jornalismo poderia ser incluído como um dos bens desse inventário antropológico, pensado como uma tópica sociocultural da expressão do imaginário social, com uma gramática específica e com uma dinâmica que perpassa concomitantemente texto e sociedade, num continum.Por isso a sugestão da combinação de mitocrítica e mitoanálise.}

Sobre os métodos elaborados por Durand, gostaria de comentar a combinação de dois deles: a mitocrítica e mitoanálise, próprios para serem aplicados a relatos, quer literários ou sociológicos, e, como proponho, a textos jornalísticos. A mitocrítica se faz sobre uma obra literária (influência mais bachelardiana) ou um autor (textos) e a mitoanálise, mais abrangente, se faz em terreno social amplo (sociedade). Os estudos de seguidores do pensamento de Durand levaram a uma ampliação da mitocrítica para a mitoanálise, reforçando um olhar histórico e sociológico sobre os mitos - mitos românticos, mitologias oficiais (nacionalsocialismo ou comunismo), a imaginária da alquimia ou da ciência etc.
Desde então, metodologicamente, toda mitanálise deverá começar pelo exame mitocrítico o mais exaustivo das "obras" - ou dos "bens" - de uma época ou cultura dada. Pinturas, esculturas, monumentos, ideologia, códigos jurídicos, rituais religiosos, modos, vestimentas e cosméticos - em uma palavra, todo o conteúdo do inventário antropológico - são igualitariamente convidados a nos informar sobre tal ou tal momento da alma individual ou coletiva (Durand citado por Pitta, 2005, p. 102).

Na minha hipótese, o jornalismo poderia ser incluído como um dos bens desse inventário antropológico, pensado como uma tópica sociocultural da expressão do imaginário social, com uma gramática específica e com uma dinâmica que perpassa concomitantemente texto e sociedade, num continuum. Por isso a sugestão da combinação de mitocrítica e mitoanálise, uma vez que o texto jornalístico transita entre sua própria linguagem codificada e o "ouvir dizer que" que serve à duração e transformação do imaginário (para Durand, passando por várias gerações) e serve também ao "ouvir dizer que" no qual se fundamenta a produção jornalística, via as rotineiras entrevistas.

Importante considerar o relato jornalístico (de qualquer matéria jornalística: hardnews, softnews, opinativa, sensacionalista, etc.) como lugar de expressão (clara ou obscura, latente ou facilmente visível) do imaginário social compartilhado por todos os sujeitos envolvidos no universo das notícias, sejam repórteres, leitores/receptores, fontes, publicitários, proprietários de veículos noticiosos, editores, anunciantes. Insisto que ambos, produtores e receptores de notícias, compartem imaginários, e por isso é que podemos estudar esse mundo imaginal tanto no texto, na observação e coleta junto aos jornalistas, como também na recepção, junto a leitores, ouvintes, telespectadores e navegadores virtuais.

Por tudo o que foi dito anteriormente, saliento a relevância e pertinência de estudos de imaginário no campo do Jornalismo. Se o imaginário tudo perpassa, a imprensa é locus fecundo de observação desses vestígios imaginais, uma vez que as notícias trazem para a vida cotidiana toda a diversidade do mundo, da política e economia à arte e entretenimento, incluindo as próprias ocorrências ordinárias, do dia-a-dia. Toma-se, então, o jornalismo como uma tecnologia de criação e reprodução de imaginários sociais, como 
fonte que alimenta com imaginários o cotidiano contemporâneo e, ao mesmo tempo, de imaginários sociais alimenta a si mesmo ${ }^{3}$. Exatamente por isso o conceito de trajeto antropológico de Durand é fundamental nessas reflexões porque, ao considerar o transitável entre o indivíduo e o social através da ponte do imaginário, nos fornece o percurso necessário para compreender as imagens trabalhadas no e pelo jornalismo.

\section{Toma-se, então, o jornalismo como uma tecnologia de criação e reprodução de imaginários sociais, como fonte que alimenta com imaginários o cotidiano contemporâneo e, ao mesmo tempo, de imaginários sociais alimenta a si mesmo}

Porém, a opção por uma teoria mais aberta para investigar o fenômeno jornalístico, especificamente nos estudos do imaginário coletivo na imprensa, requer uma outra atitude epistemológica e metodológica, mais pela via compreensiva do que explicativa, mais bem demarcada pelo enfoque nas categorias vida cotidiana e senso comum, ambas preciosas para os estudos jornalísticos em geral, e mais especialmente para a pesquisa de manifestações de imaginários no jornalismo. Legros et al. (2007), analisando os pesquisadores da temática do imaginário, dizem que a grande maioria deles tem comportamentos que definem, em geral, aquele explorador possuidor de mapas imprecisos de um território mal conhecido, e, portanto, perigoso.

E afirmam que "refletir e trabalhar sobre o imaginário supõe uma grande modéstia, pois o homem e a sociedade saem da iluminação fácil dos pressupostos aos quais se empresta fé em virtude de uma razão que (a)parece, repentinamente, frágil" (Legros et al., 2007, p. 102). Somente uma epistemologia compreensiva, como defendida por Sodré, pode abrir para a análise comunicacional um caminho teórico que saiba privilegiar o emocional, o sentimental, o afeto e o mítico. E não só para indagar sobre o encaminhamento político das emoções, como faz o pesquisador, mas igualmente aberta para qualquer instância coletiva por onde se movimenta o imaginário - no caso do jornalismo, cabe investigar na imprensa vestígios e marcas do imaginário econômico, político, religioso, científico, tecnológico, artístico, esportivo, da natureza, etc.; podendo fazer recortes específicos como, por exemplo, imaginários de jovens, mães, ecologistas, operários, leitores e até de jornalistas e as imagens que têm de sua própria profissão. É o método que Maffesoli chama de impressionismo intelectual, pelo qual o pesquisador trabalharia ao ar livre, escapando do enclausuramento das fórmulas prontas, para dar conta das ambiências (Maffesoli, 1998, p. 22).

Para tanto, continua Maffesoli, o pesquisador poderia se socorrer da metáfora como ferramenta - "uma alavanca metodológica, como foi o conceito, num tempo em que reinava a razão abstrata e a esperança em valores universais oriundos da filosofia das Luzes" (1998, p. 156) - e da descrição como técnica. Mais do que razão a priori, sugere o autor, entraria em ação uma compreensão a posteriori, que se apóia sobre uma descrição rigorosa (1998, p. 47). "Metodologicamente, sabese que a descrição é uma boa maneira de perceber, em profundidade, aquilo que constitui a especificidade de um grupo social. Quanto a isto, os diversos processos etnológicos foram disseminados por todas as ciências sociais" (1998, p.123). Maffesoli entende que os jornalistas estão cada vez mais atentos à trama social e seu cotidiano,

concedendo, ao lado de rubricas políticas, econômicas, um lugar não negligenciável às chamadas "ocorrências" (fr. "faits divers"). Eu diria que, para além dos simples clichês jornalísticos, convém dar um estatuto teórico a esse conjunto de "ocorrências". Isso pode ser feito se à observação for concedida a dignidade que lhe é de direito (Maffesoli, 1998, p. 123-124).

E eu mesma diria que, muitas vezes, só aparentemente trata-se de clichês e estereótipos na imprensa. As matérias noticiosas são carregadas de imaginários. E uma Teoria do Jornalismo mais aberta é igualmente capaz de contribuir para dar estatuto teórico a esse conjunto de ocorrências e acontecimentos, de declarações, críticas e opiniões (ver trabalhos de Bird e Dardene, Carey, Coman, Lule, e, entre os brasileiros, Barros; Albuquerque; Benetti; Moretzsohn; Gislene Silva; Juremir Machado da Silva; e Sodré). De fato, há em tudo isso um importante interesse epistemológico.

Assim, longe de ser uma abdicação do intelecto pode-se acreditar que, graças a descrições e comparações precisas, seja possível estabelecer uma tipologia operatória que permita apreender, com mais justeza, o estilo de 
vida contemporâneo. Tal descrição, pondo em jogo metáforas, analogias, poderá ser um vetor de conhecimento, muito precisamente estabelecendo grandes formas que permitam sobressair os fenômenos, as relações, as manifestações figurativas da sociabilidade contemporânea (Maffesoli, 1998, p. 128).

Para concluir, como aconselha o próprio Maffesoli, a tarefa requer que se leve a sério o sensível. "Isso se traduz na recusa a opor os fatos afetivos e os fatos cognitivos mas, em vez disso, reconhecer a dinâmica que os une sem cessar. Dinâmica em ação na vida social, dinâmica que deve se encontrar, de fato, no ato do conhecimento" (Maffesoli, 1998, p. 194). Além disso, o racional e o imaginário não devem ser tomados como categorias antitéticas, pois ambos pertencem ao universo das imagens (Silva, G., 2009, p. 213), uma vez que o imaginário não é nem abstrato nem concreto, nem racional nem irracional, é sempre ambos. Por isso, as notícias devem ser compreendidas como um exercício de produção de sentido e de entendimento do mundo que responde não só a demandas pragmáticas - apreender a realidade objetiva e rotineira - mas também a demandas subjetivas - nos elevar "para além do imediato diário" e nos situar "dentro de "imensos edifícios de representação simbólica'"' (Silva, G., 2005, p. 101).

Penso que, para estudar parte do grande acervo ou repertório imaginário que está presente, vivo, nas páginas da imprensa, devemos recorrer à contribuição da antropologia do imaginário:

A razão e a ciência apenas unem os homens às coisas, mas o que une os homens entre si, no nível humilde das felicidades e penas cotidianas da espécie humana, é essa representação afetiva, porque vivida, que constitui o império das imagens. [...] E é então que a antropologia do imaginário pode se constituir, antropologia que não tem apenas a finalidade de ser uma coleção de imagens, de metáforas e de temas poéticos. Mas que também deve ter a ambição de montar o quadro compósito das esperanças e temores da espécie humana, a fim de que cada um nele se reconheça e se revigore (Durand, 1988, p. 106).

Recupero aqui uma aproximação inspirada em modo de conhecimento do mundo e do homem próprio dos povos chamados primitivos. Esses povos, segundo Lévi-Strauss, "souberam elaborar métodos racionais para inserir, sob seu duplo aspecto de contingência lógica e de turbulência afetiva, a irracionalidade na racionalidade" (Lévi-Strauss, 1989, p. 270). Tal debate me parece importante para o jornalismo, no seu enfrentamento da questão objetividade-subjetividade na apreensão dos acontecidos, no que diz respeito a sua configuração como produto cultural e como produtor de cultura.

\section{REFERÊNCIAS}

ALBUQUERQUE, Afonso. A narrativa jornalística para além dos fait-divers. Lumina, Juiz de Fora, v. 3, n. 2, p. 69-91, jul./dez. 2000.

BARROS, Ana Taís M. Portanova. O iconoclasmo no jornalismo. Sob o nome de real: imaginários no jornalismo e no cotidiano. 2003. Tese (Doutorado) - ECA/USP, São Paulo, 2003.

BIRD, Elizabeth. The anthropology of news and journalism: why now? In: BIRD, Elizabeth. The anthropology of news and journalism: global perspectives. Bloomington: Indiana University Press, 2009.

BIRD, Elizabeth; DARDENNE, Robert. Mito, registro e histórias: explorando as qualidades narrativas das notícias. In: TRAQUINA, Nelson. Jornalismo: questões, teorias e estórias. Lisboa: Vega, 1993.

CAREY, James. A cultural approach to communication. In: CAREY, James. Communication as culture: essays on media and society. London: Routledge, 1992. p. 13-36.

Media, myths and narratives: television and the press. Newbury Park, Sage, 1988.

COMAN, Mihai. News, stories and myth: the impossible reunion? In: ERIC W. Rotherbuhler e Mihai Coman (Eds.). Media anthropology. Thousand Oaks. CA: Sage. 2005a.

DURAND, Gilbert. A imaginação simbólica. São Paulo: Cultrix/Edusp, 1988.

As estruturas antropológicas do imaginário; introdução à arquetipologia geral. São Paulo: Martins Fontes, 1997.

. O imaginário: ensaio acerca das ciências e da filosofia da imagem. Rio de Janeiro: Difel, 1998.

LEGROS, Patrick et al. Sociologia do imaginário/Frédric Monneyron, Jean-Bruno Reanrd. Patrick Legros e Patrick Tacussel. Porto alegre: Sulina, 2007. (Coleção Imaginário Cotidiano).

LÉVI-STRAUSS, C. O pensamento selvagem. Campinas, SP: Papirus, 1989.

LULE, Jack. Daily news, eternal stories; the mythological role of journalism. New York: The Guildford Press, 2001.

LULE, Jack. News as myth: daily news and eternal stories. In: ERIC W. Rotherbuhler e Mihai Coman (Eds.). Media anthropology. Thousand Oaks.CA: Sage. 2005. p. 101-110.

MACHADO, Marcia Benetti. Jornalismo e a lógica transversal do imaginário. In: II Encontro Nacional de Pesquisadores em Jornalismo, 2004, Salvador. Anais eletrônicos. Brasília: SBPJor, 2004. s/p.

. Jornalismo e imaginário: o lugar do universal. In: Dimas Kunsch. (Org.). Esfera pública, redes e jornalismo. São Paulo: E-papers, 2009. p. 286-298. 
MAFFESOLI, Michel. Elogio da razão sensível. Petrópolis, RJ: Vozes, 1998.

. O imaginário é uma realidade (entrevista). Revista Famecos: mídia, cultura e tecnologia, Porto Alegre, v. 1, n. 15, p. 74-82, ago. 2001.

MARTÍN-BARBERO, Jesús. Cartografias culturales de la sensibilidad y la tecnicidad, texto oferecido no minicurso ECA/ USP, agosto de 2008. (Texto fragmento de artigo intitulado Razón técnica y razón política: espacios/tiempos no pensados, Revista Ciencias de la Comunicación, n. 1, São Paulo, 2005).

MORETZOHN, Sylvia. Pensando contra os fatos: jornalismo e cotidiano, do senso comum ao senso crítico. Rio de Janeiro: Revan, 2007.

MORIN, Edgar. A inteligência da complexidade. São Paulo: Peirópolis, 2000.

. O cinema e o homem imaginário; ensaio de antropologia. Lisboa, Portugal: Relógio D’Água/Grande Plano, 1997.

PATAI, Raphael. O mito e o homem moderno. São Paulo: Cultrix, [s.d.]

PITTA, Danielle Perin Rocha. Iniciação à teoria do imaginário de Gilbert Durand. Rio de Janeiro: Atlântica Editora, 2005.

RESENDE, Fernando. Falar para as massas, falar com o outro: valores e desafios do jornalismo. (no prelo, Editora Autêntica/UFMG, Belo Horizonte).

SERELLE, Marcio. Jornalismo e guinada subjetiva. Estudos em Jornalismo e Mídia, Florianópolis, SC, ano VI, n. 2, p. 33-44, jul./dez. 2009.

SILVA, Juremir Machado. A questão da técnica jornalística: cultura e imaginário. Revista Famecos: mídia, cultura e tecnologia, Porto Alegre, n. 39, p. 13-18, ago. 2009.

. As tecnologias do imaginário. Porto Alegre: Sulina, 2006.

SILVA, Gislene. Jornalismo e construção de sentido: pequeno inventário. Estudos em Jornalismo e Mídia. Florianópolis, ano II, n. 2, p. 95-107, 2005.

De que campo do jornalismo estamos falando? MATRIZzes, USP, v. 1, p. 197-212, 2009.

Sobre a imaterialidade do objeto de estudo do Jornalismo, e-compós, v. 12, p. 1-14, 2009.
SILVA, Gislene. O sonho da casa no campo: jornalismo e imaginário de leitores urbanos. Florianópolis: Insular, 2009.

SODRÉ, Muniz. As estratégias sensíveis afeto, mídia e política. Petrópolis, RJ: Vozes, 2006.

SUSCA, Vicenzo. Nos limites do imaginário: o governador Schwarzenegger e os telepopulistas. Porto Alegre: Sulinas, 2007.

VOGEL, Daisi. A ficção do relato jornalístico. Caligrama Revista de Estudos e Pesquisas em Linguagens e Mídia, São Paulo, v. 1, n. 3, set./dez. 2005.

\section{NOTAS}

1 Uma versão inicial deste trabalho foi apresentada no GT "Estudos de Jornalismo", do XIX Encontro da Compós, na PUC-RJ, Rio de Janeiro, de 08 a 11 de junho de 2010.

2 Durand esclarece que a teoria do trajeto antropológico encontra-se implícita no livro $O$ ar e os sonhos, de Bachelard, tal como nas reflexões de Roger Bastide sobre as relações da sociologia e da psicanálise.

3 Imprescindível lembrarmos de $A$ instituição imaginária da sociedade (Rio: Paz e Terra, 1982) de Cornelius Castoriadis, com quem concordamos quando diz que o mundo social-histórico está indissociavelmente entrelaçado com o simbólico e que as instituições, embora só possam existir através do simbólico, não se reduzem a ele. Não cabe discordância também por dizer que o simbolismo se crava no natural e no histórico; e que não é livremente escolhido, nem escravo da funcionalidade. Mas divergimos quando afirma que "não se pode pensar as significações imaginárias a partir de uma relação que elas teriam com um 'sujeito' que as 'traria' ou as 'visaria'. Isso seria negar toda a contribuição da antropologia e da própria psicologia na compreensão de um objeto por natureza multidisciplinar. Por isso, concordamos com Durand quando aponta que em Cornelius Castoriadis (e também em Georges Balandier de Os poderes em cena) as razões políticas dos poderes aparentes são tão racionalizadas que se destacam sobre um fundo imaginário, de certa forma secundário (Durand, 1998, p. 56). Para uma leitura sobre o percurso de uma sociologia do imaginário, ver Legros, P. at al. 